\title{
Corpos na escola: reflexões sobre Educação Física e religião
}

\author{
Ana Carolina Capellini Rigoni* \\ Jocimar Daolio**
}

\begin{abstract}
RESUMO: Este artigo é fruto de uma pesquisa de doutorado a respeito da tensão entre alguns conhecimentos produzidos no âmbito da Educação Física (EF) e aqueles produzidos no âmbito religioso. O estudo constituiu-se em uma etnografia realizada numa escola pública na cidade de Campinas, SP. Foram selecionadas cinco meninas evangélicas, pertencentes a turmas de ensino médio. O objetivo foi compreender o modo como essas meninas relacionam aquilo que a igreja ensina com outras formas de gerir o corpo, que aprendem fora do âmbito religioso, e ainda, em que medida a EF exerce um papel de tensão nessa relação.
\end{abstract}

Palavras-chave: Educação Física. Corpo. Religião evangélica

\section{INTRODUÇÃo}

A partir de uma etnografia realizada numa igreja evangélica Assembleia de Deus há alguns anos ${ }^{1}$, foi possível perceber um tipo de educação religiosa direcionada especificamente aos "usos do corpo" das meninas que a frequentavam. Esse tipo de educação implicava, de alguma forma, a participação dessas meninas nas aulas de Educação Física (EF). Se no ambiente da igreja o que podíamos ver eram corpos que, por suas características físicas e gestuais, demonstravam um tipo de postura evangélica, fora dele tais características tornavam-se quase imperceptíveis diante dos olhos. Isso acontecia porque os sujeitos investigados estabeleciam

\footnotetext{
"Departamento de Ciências da Educação Física e Saúde, Universidade Federal de São João del Rei. São João del Rei, MG, Brasil. E-mail: anacarolinarigoni@yahoo.com.br

"Faculdade de Educação Física, Universidade Estadual de Campinas, Campinas, SP, Brasil. E-mail: jocimar.daolio@gmail.com.

${ }^{1} \mathrm{O}$ trabalho teve origem a partir da dissertação da autora.

2O termo "usos do corpo" faz referência à noção elaborada por Marcel Mauss (2003) no clássico texto "As técnicas corporais".
} 
adaptações e/ou acomodações entre a prática religiosa institucional e a vida cotidiana fora da igreja. A partir disso, o interesse desta pesquisa foi compreender em que medida os conteúdos da EF tensionam ou podem tensionar estes movimentos de acomodação.

$\mathrm{Na}$ busca de compreender o modo como essas meninas relacionam aquilo que a igreja ensina com outras formas de gerir o corpo, que aprendem fora do âmbito religioso e, ainda, em que medida a EF exerce um papel de tensão nessa relação, realizamos uma etnografia em uma escola pública do município de Campinas, SP, dentre algumas turmas de Ensino Médio (EM). Além do contato direto com o grupo, outros alunos, professores e funcionários também foram importantes na elaboração da pesquisa. A opção pelo EM se deve ao fato de termos percebido a importância da narrativa dos sujeitos, bem como a habilidade oral de reconstrução de suas trajetórias no que diz respeito ao tema da pesquisa. Entendemos ainda que, na idade em que se encontram, os conflitos entre ensino religioso e vida cotidiana podem aparecer de maneira mais intensa, podendo gerar mais conflitos, numa fase em que os sujeitos, supostamente, estão passando de uma relação de maior obediência e dependência dos pais para uma vida mais próxima da adulta e a consequente autonomia de comportamentos. Constatamos, empiricamente, que nessa fase muitos crentes ameaçam abandonar a igreja, negam-se a batizar-se e estabelecem um maior enfrentamento em relação aos pais. As meninas, todas pertencentes à Congregação Cristã no Brasil (CC) ou à igreja evangélica Assembleia de Deus (AD) ${ }^{3}$, foram acompanhadas durante o ano letivo de 2011, particularmente durante as aulas de EF. É preciso explicar que incluímos nas análises uma garota pertencente à igreja Batista Nova Salém, pois, apesar de hoje ela pertencer à outra denominação, durante anos ela foi da AD. A partir de suas falas sobre os motivos que levaram a família a trocar de igreja e sobre como era pertencer à $\mathrm{AD}$ percebemos que ela seria

\footnotetext{
${ }^{3}$ Entendendo a abrangência que a categoria "evangélicos" pressupõe, alertamos para o fato de que o que chamamos, ao longo do texto, de "evangélicos" diz respeito especificamente às denominações pesquisadas, ou seja, a $A D$ e a CC. É preciso dizer, ainda, que a escolha por estas duas denominações se deu pelo fato de que elas ainda se mantêm mais rígidas e conservadoras quando comparadas à outras igrejas do mesmo gênero.
}

Movimento, Porto Alegre, v. 20, n. 3, p. 875-894, jul./set. de 2014. 
uma boa informante. Sendo assim, as meninas selecionadas foram cinco: Ana Julia ${ }^{4}$, que tem 15 anos de idade e está no $1^{\circ}$ ano do EM e sua família sempre foi da AD; Sirléia tem 15 anos e estuda na mesma classe que Ana Julia. Ela também frequenta a AD desde que nasceu (como eles costumam dizer "nasceu na igreja"); Maria tem 18 anos, está no $3^{\circ}$ ano do EM (reprovou o $2^{\circ}$ ano do EM). Ela é da $\mathrm{CC}$ desde que nasceu. Seu avô é pastor de uma igreja numa cidade vizinha e, apesar dela não frequentar a mesma igreja que o avô, a família é muito rígida e vive sob sua vigilância; Renata tem 16 anos e está no $2^{\circ}$ ano do EM. Frequenta a CC há cerca de 10 anos. Renata parece mais "descolada" que as meninas já apresentadas e é o tipo de garota que enfrenta, com sutileza, os pais; Letícia, que não pertence a nenhuma das igrejas selecionadas, mas forneceu informações relevantes sobre a época que frequentava a $\mathrm{AD}$, tem 16 anos e está na mesma classe que Renata 5 .

Buscamos entender como, em termos de práticas corporais, elas relacionam um tipo de "conhecimento religioso" com aqueles produzidos em outras esferas do conhecimento que também carregam a pretensão de agenciar os corpos dos indivíduos e os cuidados de si. Apesar de termos focado o tipo de conhecimento produzido e veiculado nas aulas de EF, é preciso deixar claro que o interesse não foi a aula em si ou o trabalho pedagógico, mas a forma como os conteúdos da disciplina geravam necessidades de negociação por parte dos sujeitos no que se referia a um tipo de "uso do corpo" desejado pela educação religiosa. Além disso, tínhamos clareza sobre o fato de que o que procurávamos ultrapassava o âmbito da quadra esportiva e até da esfera escolar. Percebemos, inclusive, a separação de alguns alunos e o agrupamento de outros, interferindo diretamente numa relação de convivência mais prolongada. Possuíamos a clareza de que tudo o que ali ocorria era produto de relações que ultrapassavam os muros da escola ou as delimitações da quadra esportiva. Sendo assim, só fazia sentido

\footnotetext{
${ }^{4}$ Todos os nomes aqui citados são fictícios.

${ }^{5} \mathrm{~A}$ escolha pelas meninas não se deve ao fato de acharmos que tais implicações não atingem os meninos e homens destas denominações, mas porque desde o início o que nos chamou a atenção foi a ênfase dada aos cuidados com o corpo feminino que estão visivelmente marcados em suas aparências e gestualidades.
}

Movimento, Porto Alegre, v. 20, n. 3, p. 875-894, jul./set. de 2014. 
pensar nos comportamentos observados, compreendendo-os a partir de uma ideia de "relação" - relação entre as meninas estudadas, seus colegas e professores, os grupos que frequentavam fora da escola, a família etc. Mais do que isso, deveríamos estar atentos a essas relações no que diz respeito a outros locais ou instituições que, de alguma forma, agenciam conhecimentos e experiências corporais e que possuem ligação com o objeto em questão.

\section{Os (des)compassos entre a Educação Física e a EDUCAÇÃO RELIGIOSA}

Não tem como não lembrar daquilo que a gente aprende [na igreja]. Mas eu não engulo tudo, não. Tem gente que acha que ficar jogando bola é coisa muito praticada no mundo, mas eu acho que não tem nada a ver [Ana Julia].

Vale destacar - e estar atento a este fato é condição indispensável para que o leitor compreenda de onde vêm as noções atribuídas à EF durante o texto - que as concepções a respeito de corpo, de gestualidade, dos objetivos da EF e de seus conteúdos não são referentes ao nosso entendimento da área, mas ao entendimento das meninas estudadas e, por vezes, das outras pessoas que participaram da pesquisa. Neste caso, noções vinculadas à estética corporal, ao rendimento esportivo e ao lazer são colocadas o tempo todo pelas meninas selecionadas como aquilo que elas entendem pelo objetivo da disciplina de EF na escola. Longe de tratar esses entendimentos como equivocados, eles demonstram o que de fato é a EF para os sujeitos pesquisados. Afinal, era essa compreensão de EF que criava as tensões que tanto nos interessavam.

Ao acompanhar as alunas selecionadas pudemos compreender como elas lidam com algumas questões e como agenciam, em sua vida cotidiana, os modos de gestão corporal que chegam até elas pelas diversas instâncias, principalmente pelo conhecimento produzido pela EF. Há ainda que se levar em consideração um tipo de "entendimento nativo" sobre corpo, no qual a ideia de usos parece bem apropriada, se levarmos em consideração que os

Movimento, Porto Alegre, v. 20, n. 3, p. 875-894, jul./set. de 2014. 
evangélicos pesquisados entendem o corpo como um instrumento dado por Deus e que de seus usos depende a salvação. Neste caso, a divisão entre corpo e espírito reflete a divisão entre "mundo" e igreja (Deus).

As imposições sobre o corpo, hoje, mudaram de forma. Os sentidos atribuídos aos "usos do corpo" modificaram-se na mesma medida em que a religião se transformou. O que parece é que, num movimento simultâneo, a religião e os "usos do corpo" foram deixando de lado experiências que pertenciam à esfera pública para se tornarem experiências cada vez mais individuais. Há uma mudança na compreensão das relações entre corpo e "compromisso religioso". O que se percebe não é um desaparecimento das proibições, mas uma nova distribuição de coerções e uma maior autonomia de escolha.

O processo de secularização ${ }^{6}$, promovido pela divisão entre as esferas política e religiosa, segundo Pierucci (1997), dá condições ao crescimento dos novos movimentos religiosos. A consequência de tal processo gera o que o autor chamou de "pluralidade religiosa". É com base nesta noção - de pluralidade religiosa - que, alguns anos depois, o autor reafirma o argumento de que o sujeito se desloca para um campo religioso mais plural, feito de escolhas individuais e da diluição de vínculos comunitários anteriores. Ele afirma que o sujeito se individualiza ao mudar de religião, pois se abstrai dos vínculos herdados. Segundo a leitura weberiana de Pierucci (2006), além da "secularização", temos outro fenômeno aliado a este que influenciou no processo de racionalização do mundo, ao que o autor se refere como "desencantamento". Com base na ciência e na filosofia, as explicações sobre o mundo colocam os argumentos mágico-religiosos em segundo plano. Estes dois processos, "secularização" e "desencantamento", modificaram a noção de corpo na medida em que este foi dessacralizado. Há uma desregulação institucional que modifica os modos de crer na contemporaneidade. "As instituições religiosas continuam a perder

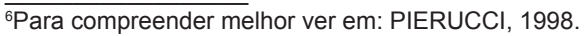

Movimento, Porto Alegre, v. 20, n. 3, p. 875-894, jul./set. de 2014. 
a sua capacidade social e cultural de imposição e de regulação das crenças e das práticas" (HERVIEU-LÉGER, 1999, p.46). Isso não significa que as noções religiosas deixaram de gerir, em certa instância, o corpo e suas práticas. Os referenciais religiosos continuam a existir, mas a forma como operam transforma-se continuamente. Se, como afirma Almeida (2010), o que parece é que as coisas religiosas estão ao mesmo tempo se expandindo e se dissolvendo, então a ideia de desencantamento parece não se sustentar e, portanto, sugerimos que não serve como argumento para afirmar que as "referências sagradas" deixam de gerar implicações sobre os "usos do corpo". O fato é que, mesmo parecendo perder força e autoridade sobre a vida cotidiana, a religião ainda é significativa quando o que está em jogo é o agenciamento do comportamento dos indivíduos.

Esta tensão permanente entre o que é religioso e o que é secular (ou mundano) pode ser exemplificada em várias falas das meninas como, por exemplo, nesta colocação de Ana Julia: “ $A$ única coisa que a gente não pode ter é vaidade". É neste sentido que Paula Montero (1999) argumenta que diferentes linhagens teóricas foram atreladas aos estudos de segmentos religiosos quase de forma padronizada, de forma que o protestantismo, por exemplo, sempre aparece vinculado à teoria weberiana, que vincula valores a comportamentos. Nesse caso, valores que negam a vaidade e a preocupação com a aparência estão intimamente relacionados aos modos de se comportar de pessoas que, como Ana Julia, frequentam as igrejas em questão. Esse tipo de comportamento, relacionado aos cuidados com o corpo, é construído com base nos valores pregados na e pela igreja. Mas, apesar da estreita relação entre evangélicos e comportamentos vinculados a valores morais, Almeida (2010, p. 374) afirma que percebemos hoje certo "descompasso" entre o ensinamento institucional e a prática dos fiéis. "Não é raro o líder pregar certos padrões de comportamento e as pessoas o seguirem parcialmente, mantendo suas próprias regras". Ele ainda afirma que cada vez menos há coincidência entre a identidade religiosa e a prática correspondente. Ao considerar que a igreja, na tentativa de agenciar os sujeitos, entra em tensão com outras instituições,

Movimento, Porto Alegre, v. 20, n. 3, p. 875-894, jul./set. de 2014. 
podemos compreender o fato das igrejas estarem, aos poucos, abrindo espaço para coisas que antes eram "mundanas" demais para serem permitidas.

O termo "descompasso" pode sugerir duas formas de compreender a relação entre ensinamento institucional e prática cotidiana. No sentido trazido pelo dicionário (FERREIRA, 2001) falar em descompasso é fazer referência a algo fora de ordem, ou de regularidade. Nesse sentido não há acordo entre uma esfera e outra. Podemos ainda pensar em descompasso partindo do conceito de compasso (instrumento, composto de duas hastes que se articulam para traçar circunferências). Nesse caso, o termo teria sentido se pensado como um traço fora de circunferência. Na verdade, os dois sentidos são muito parecidos e servem para explicar a falta de regularidade entre as esferas já citadas. No entanto, utilizamos o segundo sentido por achá-lo mais interessante para pensar em "o que vem depois". O fato de um descompasso não permitir formar um tipo de circunferência com formas regulares não significa que nenhum desenho será formado. Essa falta de medida irá resultar em outros desenhos, com outras formas e medidas que, mesmo não sendo regulares, apontam para algo que mudou durante o movimento do compasso. Pensando analogamente, esse tipo de movimento - pensado como o desencontro entre ensino institucional e prática dos fiéis - sempre houve, ainda que em formas e intensidades diferentes. Podemos pensar, ainda de forma análoga, que esses movimentos resultam em desenhos específicos. São essas formas e desenhos, que vêm se configurando no plano das práticas corporais e que se formam a partir deste "desencontro", que interessam aqui. Nesse sentido, é como se do próprio descompasso pudéssemos visualizar outro tipo de compasso, não novo, mas com formações diferentes, em que os fiéis pentecostais vão traçando, à sua forma, desenhos diversos, mas que a meu ver, apresentam certas regularidades. Talvez seja possível falar que esses acordos vão sendo estabelecidos com conhecimento e "permissão" (num sentido velado) da instituição religiosa, que vai assimilando as mudanças e se acomodando às novas demandas da "fé". Os exemplos a seguir demostram uma

Movimento, Porto Alegre, v. 20, n. 3, p. 875-894, jul./set. de 2014. 
mudança nas dinâmicas de transmissão religiosa e, principalmente, nas práticas em relação ao padrão comportamental, o que significa que pensar nas experiências relacionadas às práticas religiosas sugere a reflexão a respeito de suas implicações sobre o corpo, como podemos perceber a partir da afirmação abaixo:

A educação física está o tempo todo provocando o olhar do outro [Sirléia].

O entendimento das alunas sobre EF parece o de uma disciplina que tem como finalidade ensinar os cuidados com o corpo (num sentido restrito aos padrões de beleza e saúde) e as modalidades esportivas (no sentido restrito ao do treinamento e da técnica). Paralelamente aparecem ideias como ensinar a prática de atividade física para além da vida escolar, educar para o lazer, e a relação, um tanto diluída, entre EF e socialização. Nesse sentido, não são apenas as meninas estudadas que, por serem evangélicas, possuem essa compreensão da EF. O que há de particular nesse caso é a maneira como a instituição religiosa entra em tensão com esse conhecimento que, para elas, pertence ao escopo da área.

Tal visão de EF torna-se um "prato cheio" para o discurso oposto da igreja, que prega justamente o enaltecimento de valores morais e não físicos. A frase citada como epígrafe desse tópico demonstra de maneira muito clara esta afirmação e o que, de fato, incomoda a igreja quando o assunto é a EF. A exposição e o uso do corpo em práticas tidas como "mundanas" pela igreja parece o ponto-chave de análise.

$\mathrm{Eu}$ acho que a igreja cuida da minha pessoa espiritual, da minha alma. E a EF me ensina a cuidar da minha pessoa física, do meu corpo. Para a minha igreja, eu sei que eles acham que só tem que se preocupar com a alma. Mas eu, Maria, acho que a gente tem que cuidar sempre dos dois juntos. O que é que adianta a gente cuidar da alma e não cuidar da vida?[Maria].

O interessante na fala de Maria é a forma como ela opõe o ato de "cuidar da alma" ao de "cuidar da vida". Trata-se, basicamente, 
da mesma oposição corrente entre aquilo que é da igreja e o que é mundano, mas a forma como ela formula deixa clara uma posição tomada diante dessas oposições. É como se ela afirmasse que, mesmo algo sendo "do mundo", pode ser necessário e desejado por ela de forma legítima.

Após um comentário semelhante ao de Maria, Ana Julia afirmou que ao ficar observando as colegas jogarem sempre sentiu muita vontade de participar das aulas de EF. Certa vez, após conversar com sua mãe, decidiu ir contar ao pastor sobre os constrangimentos pelo qual passava por não participar, inclusive em relação à cobrança do professor que, segundo ela, sempre insistia para que ela mudasse de atitude e participasse. Questionada sobre a resposta do pastor ela disse que ele não permitiu que ela utilizasse calça para ir às aulas de EF, mas que ela podia participar de algumas atividades, como o vôlei, por exemplo. Ao questioná-la sobre o porquê da decisão do pastor, ela explicou que para ele isso poderia "denegrir" a imagem da igreja, pois Deus não gosta de tais atitudes e em casos como esse o espírito santo deixa de habitar o corpo da pessoa.

Acho até estranho o pastor ter deixado ela jogar vôlei. Uma vez, quando a gente ainda ia na $\mathrm{AD}$, a minha irmã disse para o pastor que ia jogar só vôlei, porque não tinha contato corporal como o futebol e tal, mas ele disse que era uma atividade muito vulgar [Letícia].

Tal afirmação demonstra o quanto a visão religiosa caminha para mudanças e adaptações. Mas, para além das mudanças na esfera religiosa, o que víamos se modificando era a visão delas sobre a EF. Se, na pesquisa de campo realizada anteriormente com meninas que cursavam o ensino fundamental, não percebíamos em seus discursos uma visão de EF tão relacionada às questões estéticas e de saúde, agora elas parecem compor aquilo que na visão das meninas é o objetivo da disciplina.

Se os discursos que relacionam a EF ao ato de "malhar" para ficar bonita e, ainda, à prática de atividades físicas em academias

Movimento, Porto Alegre, v. 20, n. 3, p. 875-894, jul./set. de 2014. 
não apareciam na pesquisa anterior, agora parecem compor a parte principal da disciplina na opinião das meninas selecionadas.

Essas são questões importantes no que diz respeito à própria oposição da visão religiosa quando o assunto é a EF. Uma vez que as meninas relacionam as aulas de EF ao corpo bonito, à sensação de prazer ao praticarem determinadas atividades físicas em horários e locais de lazer e, de maneira geral, aos cuidados com o corpo, fica mais fácil entender as preocupações presentes no discurso religioso. Ainda que essas questões apareçam diluídas em seus discursos, elas explicam que se entregar ao deleite de um jogo, por exemplo, é visto como algo perigoso.

Compreendendo a EF do ponto de vista das Ciências Humanas podemos considerá-la como uma disciplina que visa a uma ampliação em relação às experiências corporais, apesar desse não ser seu objetivo último. Bracht (1997, p. 22), ao elaborar uma discussão sobre a especificidade pedagógica da cultura corporal do movimento, alerta que o saber conceitual de que trata a EF envolve um duplo caráter. Tal ambiguidade pode ser representada a partir de duas questões: a especificidade da área é garantida por um tipo de "saber fazer" e por um "saber sobre o fazer". Bracht explica que, ao passo que o movimento humano é tomado como objeto da área e isso se torna um consenso, criamos outro tipo de polarização. Nesse caso o debate parte da preocupação entre privilegiarmos uma educação "do" ou "pelo" movimento ou ambas. Relacionada a uma ideia de cultura corporal do movimento, rapidamente o saber sobre o movimentar-se foi incorporado como objetivo da EF na escola e, como consequência, desenvolveu-se, segundo o autor, o "pré-conceito de que o que se estava propondo, nesse caso, era transformar a EF num discurso sobre o movimento, retirando o movimentar-se do centro da ação pedagógica em EF" (BRACHT, 1996, p. 25). Buscando ampliar a ideia a respeito do movimentar-se humano e suas relações com o conhecimento da realidade e da comunicação com o mundo, Bracht sugere que a EF deve estar preocupada com a educação estética e com a educação da sensibilidade, 'o que significa dizer 'incorporação'

Movimento, Porto Alegre, v. 20, n. 3, p. 875-894, jul./set. de 2014. 
não via discurso, e sim via 'práticas corporais"”. É dessa forma que Bracht termina seu artigo afirmando que o desafio parece ser: "nem movimento sem pensamento, nem movimento e pensamento, e, sim, movimentopensamento" (BRACHT, 1996, p. 27, grifos do autor).

Ainda que o referencial teórico de Bracht seja outro, esse conceito nos remete à ideia desenvolvida por Le Breton (2009) a respeito das possibilidades de uma experiência afetiva do movimento. Nesse caso, o professor deve garantir essa experiência na escola para que fora dela ela possa acontecer. Para além dos conteúdos e objetivos da disciplina, entendemos que essa deve preparar o aluno para o mundo do lazer e para a vivência das práticas lúdicas para além da idade escolar, enriquecendo a construção da cultura de movimento.

Se há uma linha de pensamento na EF que a entende a partir desses conceitos e códigos, não há como não fazer menção a outras formas de entendê-la que, na prática, ainda estão muito presentes na área. Ao longo da história a EF vem veiculando conhecimentos sobre o corpo, assumindo como sua função temas que dizem respeito à beleza, à força física, às formas "bem definidas", às habilidades motoras, ao rendimento etc. O que afirmamos é que esse tipo de saber, mesmo sendo contraditório àquele difundido por professores e pesquisadores que pensam a área a partir das Ciências Humanas, é ainda muito recorrente nas escolas brasileiras.

\section{Os conteúdos da Educação Física}

Samba é complicado, muito sensual [Maria].

Muitas foram as questões presentes nas narrativas das meninas, que dizem respeito a dança. De maneira geral, para todas elas essa é, dentre todas as práticas corporais, a mais "mundana". Numa aula teórica sobre os tipos de samba as opiniões emitidas podem se resumir a: "O samba não é coisa de Deus". Para as 
meninas, em geral, dançar é uma forma de se exibir. Nas palavras de Renata:

Você chama a atenção, você rebola e a pessoa começa a reparar mais em você. Aí eles acham que o outro cai em erro no pensamento, né?

Ainda que elas relacionem tal prática com aquilo que é "desaconselhado" pela igreja, a maioria delas afirma que sendo um conteúdo da aula, é possível justificar, em partes, a realização de tal atividade.

Numa aula de EF eu até poderia dançar, mas nunca poderia ir numa balada, por exemplo, dançar fora da aula, nem pensar. Quer dizer, na real, se fosse pela igreja eu não poderia dançar nem na escola [Sirléia].

Nesse sentido, mesmo sabendo que a igreja condena tal prática, Sirléia parece perceber as diferenças entre o que a igreja e a escola demandam. Ela ainda complementa dizendo que: "É Deus que vai me julgar e não os outros. E se Deus é Deus, ele tem que entender que eu preciso fazer as coisas que são da escola". Tal afirmação me parece perspicaz justamente porque ela aplica o mesmo argumento de "obrigatoriedade" presente na instituição religiosa para a instituição escolar. Se para a igreja seus membros precisam entender e agir segundo os conhecimentos de Deus, Sirléia inverte a lógica e diz que é Deus quem deve entender sua necessidade prática. Nesse sentido, ela reconhece o caráter obrigatório da aula.

Esse caráter de obrigatoriedade parece se aplicar para a maioria dos conteúdos. No entanto, quando o que está em questão são as festas juninas, o argumento perde a autoridade. Nas palavras de Letícia e Renata, dançar ou participar de uma festa dessas "é como fazer despacho, macumba". Para elas, a igreja condena qualquer forma de idolatria e se envolver com isso é "se contaminar".

Algo semelhante ocorre em relação à capoeira. Dentre todos os conteúdos que compõem o currículo da EF a capoeira é o que mais gera constrangimentos em alunos evangélicos. Para as

Movimento, Porto Alegre, v. 20, n. 3, p. 875-894, jul./set. de 2014. 
igrejas estudadas a capoeira é uma prática corporal absolutamente relacionada às religiões afro-brasileiras, o que é combatido por eles na mesma proporção que o demônio. Aliás, para alguns evangélicos, o demônio é o próprio representante dessas religiões.

Eu não faria, tenho medo dessas coisas, ficar mexendo com coisa do demônio, ui, ui. E olha que eu não sou ignorante, não, eu sei que a igreja é chata com várias coisas, mas com capoeira eu também sou [Sirléia].

Enfim, muitas são as questões que envolvem a dança, o ritmo, a música e a capoeira e que podem ser pensadas numa relação de tensão entre um tipo de agenciamento (EF) e outro (igreja). Mas os exemplos não se limitam a estas práticas, ao contrário, se estendem para as modalidades esportivas. Certa vez, ao citarem os "atletas de cristo", Maria comentou em tom irônico: "Esses aí não são do nosso Cristo, não, podem ser de outro, mas do nosso, não [risos]".

Uma das principais questões em torno da desaprovação das práticas esportivas por parte da igreja diz respeito à noção de competição. É possível para os evangélicos, em alguns casos, participar de atividades esportivas, mas nunca competir. Contavase na escola que uma aluna evangélica havia sido selecionada, havia pouco tempo, em uma "peneira" semiprofissional de uma equipe de voleibol, mas não aceitou entrar para o time porque os pais proibiram. Os "bochichos" nos corredores da escola giravam em torno das críticas ao tipo de religião que ao invés de ajudar atrapalha a vida do fiel.

Certa vez, uma professora da escola, que pertencia a $\mathrm{AD}$, emitiu-nos sua opinião sobre o jogo.

O jogo, mesmo esportivo, é algo sem noção, tem tentação, tem azar, tem vaidade com o corpo, não é aconselhável. Claro que na aula eles podem fazer. Agora, ficar satisfazendo o corpo quando não é obrigado é se desvirtuar. Pra que ter vaidade?

$\overline{{ }^{7} J o g a d o r e s ~ d e ~ f u t e b o l ~}$ conhecidos por pertencerem a grupos evangélicos.

Movimento, Porto Alegre, v. 20, n. 3, p. 875-894, jul./set. de 2014. 
Muitos são os exemplos relacionados aos esportes como práticas "mundanas". Para além disso, é possível apontar para uma questão específica que parece colocar o tempo todo o conhecimento religioso em confronto com a EF, referimo-nos à questão do "mostrar-se". Expor-se corporalmente, ser notada enquanto "corpo" parece, do ponto de vista das meninas, ser o principal fator que coloca a EF em tensão com a religião. Ainda que os objetivos da disciplina não tenham relação com a erotização dos corpos e do movimento, no entendimento dos membros das igrejas estudadas ela parece estar relacionada a essas questões, o que torna a EF uma prática, muitas vezes, desaconselhada. A possibilidade de "ser notado" é algo incitado pela EF. Não estou afirmando que um professor, ao desenvolver uma atividade, provoque seus alunos à exposição conscientemente. A ideia de estar disponível ao olhar do outro pode não se aplicar a todas as situações e, ainda que isso não ocorra sempre de forma intencional, determinada parte dessa disciplina, ainda que não seja o modelo de EF que defendamos, está relacionada a um desejo de "destacar-se". Uma EF pautada no modelo de "esportivização", implica a "obrigação" de ser "melhor" tecnicamente do que o oponente e coloca os alunos em posição de evidência constantemente. A chance de se sobressair numa determinada prática corporal e ter o destaque necessário a uma futura profissionalização reforça o objetivo de "ser notado", o que não deveria ter espaço no contexto escolar. Mesmo que deixemos de lado as competições com vistas aos níveis mais altos de rendimento e pensemos em níveis mais baixos, como numa simples competição durante a aula, por exemplo, percebemos que a simples chance de ser observado pelo professor, ou até mesmo por uma garota pela qual um menino esteja apaixonado (ou vice-versa) coloca em questão a vontade de "ser notado". O que queremos dizer, exagerando na oposição para elaborar o argumento, é que enquanto a igreja estimula um tipo de "esconder-se", a EF estimula o "mostrar-se". Ambas estimulam uma preocupação com si mesmo, mas com meios e fins diferenciados. Nesse quesito, até mesmo a roupa que devem utilizar tem papel importante para ambas as práticas. Para praticar atividades físicas é aconselhável estar com

Movimento, Porto Alegre, v. 20, n. 3, p. 875-894, jul./set. de 2014. 
os calçados e roupas adequados. Na mesma medida em que para ser um "bom crente" é necessário saber vestir-se com "pudor".

Nesse sentido, não faz parte do cotidiano das meninas estudadas correr, pular, sentar com as pernas afastadas, andar de bicicleta ou dançar. As experiências por elas vividas parecem limitadas diante de crianças que não têm seus corpos controlados e vigiados pela igreja. Quando a EF propõe uma gama de gestos pelos quais elas ultrapassam a barreira comum do "movimentarse" é como se elas precisassem estar dispostas a "se permitirem" tal feito. A EF, ainda que nem sempre ${ }^{8}$, motiva os alunos a uma ampliação dos gestos e experiências do movimento. Na medida em que ela se depara com corpos que foram educados a reduzir e não a ampliar suas experiências de movimento é que ela pode gerar tensão e reflexão por parte das meninas quanto aos "usos do próprio corpo".

Ele [o pastor] falou que na EF, por exemplo, é para gente fazer de uma forma decente, tipo não ficar se agachando tanto, cuidar com as poses na hora de alongar. Para você não provocar o olhar do homem. Porque ele falou assim: se você provocar o homem para estas coisas, é normal que ele vai querer e vai fazer você fazer o que ele quer. $\mathrm{E} a \mathrm{EF}$ tá o tempo todo provocando isso [Sirléia].

É como se, na visão dessas alunas, tivéssemos de um lado uma instituição disciplinadora (EF), que espera determinados comportamentos dos alunos através da prática pedagógica de conteúdos específicos e, do outro lado, outra instituição disciplinarizadora (Igreja) que também espera certos comportamentos através da aplicação de seus conteúdos religiosos. Quando a referência é a EF (ou aquilo que ela representa no imaginário dos alunos), essas meninas acham que devem possuir um corpo aceitável diante dos padrões impostos. Quando a referência é a igreja o valor repassado visa a não profanar o corpo.

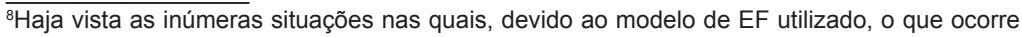
é justamente a negação da experiência do movimentar-se, reduzindo e não ampliando as possibilidades corporais dos alunos.

Movimento, Porto Alegre, v. 20, n. 3, p. 875-894, jul./set. de 2014. 
Para a religião dessas meninas o corpo é visto como "sede do Espírito Santo". Portanto existem "práticas desejáveis" (permitidas) e "práticas mundanas" (desaconselháveis). Esses termos, longe de serem apenas "deduzidos" e ressignificados no texto, são expressões correntemente utilizadas pelas meninas.

De qualquer modo, ao explicarem o porquê da tensão existente entre os conteúdos da EF e o que aprendem na igreja, as meninas dão a entender que a justificativa possível para a "implicância" da igreja com a EF está pautada na ideia de que, enquanto a igreja parece limitar as experiências corporais, a EF tem como objetivo ampliá-las. Nesse sentido, a EF - por meio dos esportes, das danças, das lutas, dos jogos e das ginásticas ${ }^{9}$ - teria como objetivos proporcionar o maior número de experiências possíveis das/nas práticas corporais, bem como contribuir com o aprendizado das formas de cuidados corporais, a partir das noções de saúde, beleza e qualidade de vida.

Interessante também é o fato de as meninas estudadas estabelecerem uma relação entre as práticas corporais presentes na EF e a sensação de prazer. Se na igreja elas aprendem que devem evitar o "prazer da carne", na EF elas entendem que as sensações físicas estão diretamente relacionadas aos conteúdos e objetivos. $\mathrm{O}$ próprio fato de designarem à EF a tarefa de ensinar os cuidados com o corpo a torna alvo de crítica por parte da igreja. A sensação de prazer por estar "bonita" e ter alcançado um corpo nos padrões impostos pela sociedade é movida pela vaidade, sentimento este desaconselhado pela igreja.

\section{Considerações finaIS}

Entendemos que uma aula de EF, na qual o professor esteja atento às diferenças de valores que as diversas práticas possuem para seus alunos, deve possibilitar a cada um a reflexão a respeito

${ }^{9}$ Apesar de as meninas saberem que todos esses são conteúdos da EF elas sempre demonstraram achar que o esporte é o principal deles.

Movimento, Porto Alegre, v. 20, n. 3, p. 875-894, jul./set. de 2014. 
dos múltiplos argumentos existentes sobre o tema em questão. $\mathrm{Ou}$ seja, a aula deve ser o espaço no qual os alunos podem contrapor aquilo que aprenderam, seja no âmbito religioso ou em outro qualquer, com um tipo de conhecimento próprio da escola e do racionalismo científico. Nesse sentido, permanecem em nossas reflexões as seguintes questões: será que a EF tem oferecido possibilidades de reflexão e de ressignificação do corpo a partir dos conhecimentos produzidos e experimentados na escola? A EF tem se diferenciado, em termos de reflexão, daquilo que a igreja faz? A EF tem sido capaz de construir um "saber desencantado", capaz de contrapor, tensionar e dialogar com o "saber encantado" oriundo do campo religioso?

Se utilizando a justificativa da liberdade religiosa alguns alunos se negam a participar de certas atividades, vimos que a noção de "obrigatoriedade" do currículo escolar é capaz de contrapor esse discurso. No entanto, mesmo a obrigatoriedade sendo uma garantia que o professor e a escola têm a seu favor, ela, por si só, não garante que os alunos se sintam à vontade realizando a atividade. Se parece utópico desejar que os alunos participem porque de fato sentemse bem e acham importante, mais utópico ainda é acreditar que só a obrigatoriedade vai legitimar a EF na escola por muito mais tempo. É preciso refletir sobre o que legitima sua sobrevivência no ambiente escolar. Não se trata de subjugar os alunos, como numa outra espécie de doutrina, mas de fornecer aparatos que permitam e motivem o exercício da reflexão.

Partimos do pressuposto que o professor de EF deve garantir a experiência dos alunos nas práticas corporais que compõem o currículo. O professor deve mediar a construção da relação que o aluno cria com as práticas corporais, seja essa relação da forma que for. Somente dessa maneira o professor terá a chance de contrapor o conhecimento sobre o corpo que os alunos trazem de outras instituições. Não significa que ele precise se preocupar em dialogar especificamente com a religião, mas possibilitar aos

Movimento, Porto Alegre, v. 20, n. 3, p. 875-894, jul./set. de 2014. 
alunos uma visão de corpo produzida na área. Isso, apesar de não garantir que esta seja a melhor forma de compreender o corpo e as práticas corporais, garante a ampliação da visão do aluno sobre corpo, práticas corporais e temas relacionados à disciplina de EF. 


Bodies in school: reflections on Physical Education and
religion
Abstract: This article is the result of a doctoral research about
the tension between some knowledge produced within Physical
Education (PE) and those produced within the religious scope.
It was an ethnographic study conducted in a public school in the
city of Campinas, SP, Brazil. Five Evangelical girls were selected
from high school classes. The goal was to understand the way
those girls relate church teachings with other ways to manage
their bodies that they learn outside religion, and to which extent
PE plays a tensioning role in that relation.
Keywords: Physical Education. Body. Evangelical religion

Cuerpos en la escuela: reflexiones sobre Educación Fisica
y religión
Resumen: Este artículo es el resultado de una investigación
doctoral sobre la tensión entre algunos conocimientos
producidos dentro de la Educación Física (EF) y los producidos
en la esfera religiosa. El estudio constituye una etnografía
realizada en una escuela pública en la ciudad de Campinas-
SP. Se seleccionaron cinco niñas evangélicas pertenecientes a
las clases de la escuela secundaria. El objetivo fue comprender
cómo estas niñas relacionan lo que la iglesia enseña con otros
medios de manejar el cuerpo, que aprenden fuera del ámbito
religioso, y también hasta qué punto tiene la EF un papel de
tensión en esta relación.
Palabras clave: Educación Física. Cuerpo. Religión evangélica.

\section{REFERÊNCIAS}

ALMEIDA, R. de. Religião em transição. In: Horizontes das ciências sociais no Brasil: Antropologia. São Paulo, ANPOCS, 2010. p. 367-405.

BRACHT, V. Educação Física: conhecimento e especificidade. In: SOUSA, E. S.; VAGO, T. M. Trilhas e partilhas: educação física na cultura escolar e nas práticas sociais. Belo Horizonte; Gráfica e Editora Cultura 1997. p. 13-23.

BRACHT, V. Educação Física no $1^{\circ}$ grau: conhecimento e especificidade. Revista Paulista de Educação Física, São Paulo, supl. 2, p. 23-28, 1996.

FERREIRA, A. B. de H. Miniaurélio Século XXI: o minidicionário da língua portuguesa. 5. ed. Rio de Janeiro: Nova Fronteira, 2001. 
HERVIEU-LÉGER, D. O peregrino e o convertido: a religião em movimento. Lisboa: Gradiva, 1999.

LE BRETON, D. As paixões ordinárias: antropologia das emoções. Petrópolis, RJ: Vozes, 2009.

MAUSS, M. Sociologia e antropologia. São Paulo: Cosac Naify, 2003.

MONTERO, P. Religiões e dilemas da sociedade brasileira. In: MICELI, S. O que ler na ciência social brasileira (1970-1995): antropologia. São Paulo: Sumaré; 1999. v. 1.

PIERUCCI, A. F. Reencantamento e dessecularização: a propósito do auto-engano em sociologia da religião. Novos Estudos CEBRAP, São Paulo, n. 49, p. 99-117, nov. 1997.

PIERUCCI, A. F. Religião como solvente: uma aula. Novos Estudos, São Paulo, n. 75, jul. 2006.

PIERUCCI, A. F. Secularização em Max Weber: da contemporânea serventia de voltarmos a acessar aquele velho sentido. Revista Brasileira de Ciências Sociais, São Paulo, v. 13, n.37, jun. 1998.

RIGONI, A. C. C. Marcas da religião evangélica na educação do corpo feminino: implicações para a Educação Física Escolar. 162 p. Dissertação (Mestrado em Educação Física) - Faculdade de Educação Física.,Universidade Estadual de Campinas, Campinas, 2008. Disponível em: <http://libdigi.unicamp.br>.

Endereço para correspondência:

Ana Carolina Capellini Rigoni

Rua André Filipaki, 50

Bairro Alto da Glória

Irati, Paraná

CEP: 84500-000

Recebido em: 23.06.2013

Aprovado em: 19.03.2014

Movimento, Porto Alegre, v. 20, n. 3, p. 875-894, jul./set. de 2014. 